\title{
The Differences in Multiple Intelligences between the Students of Jordan University of Science and Technology
}

\author{
Samer M. Ayasrah ${ }^{1} \&$ Abdalrahman H. Aljarrah ${ }^{2}$ \\ ${ }^{1}$ Faculty of Since and Arts, Jordan University of Science and Technology, AL- Ramtha- Jordan \\ ${ }^{2}$ The Ministry of Education, The Hashemite Kingdom of Jordan \\ Correspondence: Samer M. Ayasrah, Faculty of Since and Arts, Jordan University of Science and Technology, AL- \\ Ramtha- Jordan
}

Received: March 29, 2020

Accepted: May 1, 2020

Online Published: May 12, 2020

doi:10.5430/ijhe.v9n4p35

URL: https://doi.org/10.5430/ijhe.v9n4p35

\begin{abstract}
This study aimed to recognize the differences in multiple intelligences among the students of Jordan University of Science and Technology with its relationship to gender, academic year, and achievement. The study sample consisted of 349 male and female participants. It used a descriptive analysis, the MacKenzie scale for multiple intelligences, which consisted of 9 dimensions and 10 paragraphs per dimension. According to its findings, the average range for all domains of multiple intelligences was 3.70. This value implied that the average students' responses were accepted. It showed there was not any statistically significant differences at $\propto \geq 0.05$ in the students' results which could be attributed to gender and academic year. Also, there were not statistically significant differences at $\propto \geq 0.05$ in the students' results for the musical and existential dimension attributed to achievement and there were statistically significant differences for the other dimensions.
\end{abstract}

Keywords: multiple intelligences, achievement, academic year, Jordan University of Science and Technology

\section{Introduction}

The theory of multiple intelligence has immensely contributed to the development and enrichment of education. It has also prompted a significant shift in the space of psychological and educational heritage, both theoretical and experimental.

In 1983, Howard Gardner introduced the theory of multiple intelligences, which took a different course from other intelligence theories in their interpretation of the nature of intelligence. In his theory, Gardner points out that all children are born with multiple mental abilities, weak and strong alike. Effective education will develop the weak competencies of the learner while consolidating what was strong. Gardner moved away from linking intellectual competencies with mechanical heredity that robbed any will for education. He also opposed traditional intelligence tests, because, in his view, they did not do justice to the actual intelligence level of the person being tested; rather they focused on only certain aspects of intelligence. Gardner stressed that no student was better than their counterpart but that differences in intelligence existed. Since then, his theory has become an effective tool used by many educators to improve their teaching and learning processes (Shalk, 2002; Jaber, 2003; Abdelkader et al, 2007) (Chen \& Gardner, 2005, 79; Saricaoglu \& Arikan, 2009, 111).

The following describes the types of intelligences: Linguistic intelligence describes the ability to perceive and generate spoken and written language. Logical-mathematical intelligence involves the ability to appreciate and utilize numerical, abstract, and logical reasoning to solve problems. Musical intelligence entails the ability to create, communicate, and understand meanings made out of sound. Spatial intelligence denotes the ability to perceive, modify, transform, and create visual and/or spatial images. Bodily-kinesthetic intelligence deals with the ability to use all or parts of one's body to solve problems or fabricate products. Naturalistic intelligence concerns the ability to distinguish among critical features of the natural environment. Interpersonal intelligence describes the ability to recognize, appreciate, and contend with the feelings, beliefs, and intentions of other people. Intrapersonal intelligence involves the ability to understand oneself including emotions, desires, strengths, and vulnerabilities and to use such information effectively in regulating one's own life. 
It was Göğebakan (2003) who put forth the principles of multiple intelligence theory as the following:

1. Individuals should be motivated to use their preferred intelligences in learning.

2. Instructional activities should request different forms of intelligence.

3. Assessment of learning should measure multiple forms of intelligence.

The purpose of this study is to examine the differences in multiple intelligences among the students of Jordan University of Science and Technology with its relationship to gender, academic year, and achievement. Results contribute awareness to the self knowledge of the students as well as to develop suggestions for programs to enhance their academic achievement levels and to be a reference for further studies.

\section{Literature Review}

Based on analysis and inferences drawn from across literature, it is noticeable that a large number of researchers are agreeing that the theory of multiple intelligences is the way of the future. Since recently, scholars have been pointing out how this theory is having a significant impact on modern educational and learning process. Also, several studies have been conducted on the theory of multiple intelligences and how the idea relates to many variables.

For instance, Abdul Qadir and Abu Hashem (2007) have studied the nature of the global construction of intelligence from the point of view of Gardener's classification. Also, through their works, they have determined the relationship connecting multiple intelligence, self-sufficiency, problem solving, and educational achievement. They have also demonstrated how gender, educational level, and specialization impact the improvement and expression of multiple intelligences. The most important results were the absence of statistically significant differences between the mean scores of males and females in multiple intelligences. The absence of a statistically significant difference affects the triangular interaction between species, specialization, and the educational stage on multiple intelligences.

The F. Ebru (2010) study aimed to determine the relationship between multiple intelligences and the level of academic attainment of secondary students. It put forth that the identification of multiple intelligences among students will contribute to students' knowledge and self-abilities. Plus, it developed proposals for programs that will improve their academic achievement.

In Ryan's study (2013), he sought to know the patterns of multiple intelligences among secondary school students. He also searched for how to identify differentiation in their multiple intelligences according to a set of variables: gender, grade, academic track, and the level of achievement in mathematics. The study identified the multiple intelligences common among students such as social, personal, verbal, kinesthetic, musical, mathematical, spatial, and natural. It also showed that there were statistically significant differences according to gender in verbal and musical intelligence in favor of female students, as well as in the kinesthetic and natural for the benefit of males.

In 2014, Al-Rashid conducted a study aimed at identifying the multiple intelligences of the students of the Faculty of Science and Arts and its relation to some variables. The study was carried out on a sample of 732 female students from the scientific and humanities departments and the higher diploma. The McKinsey scale was used to achieve the study objectives. The study revealed that personal intelligence was first ranked, then social and logical intelligence, linguistics, physical, physiological, spatial, and musical in the end.

Saidi's study (2015) aimed to identify the multiple intelligence patterns of 12th graders in Oman. The study was conducted on a sample of 175 students, it used the Mackenzie Scale, and consisted of 30 paragraphs for measuring seven types of multiple intelligences. The results of the study indicated a difference in the levels of multiple intelligences in the study sample. It also showed a correlation between the patterns of multiple intelligences prevailing in the study sample and their academic achievement.

In his study, Alawneh (2016) aimed at identifying the multiple intelligences among the students of Al-Quds Open University in Nablus Branch. The sample of the study consisted of 368 students. They used the Mackenzie Scale, consisting of a 90-item list. The results revealed that the level of multiple intelligences among the students of Al-Quds Open University is average. There were statistically significant differences in multiple intelligences in the study sample. Due to the distance of the study, the macro changed and the interaction between the gender variable, the faculty and the academic level. The results showed no statistically significant differences in the study sample in multiple intelligences due to the variables of estimation, place of residence, age, and the double and triple interaction between these variables. 
The study of Ben Zina in (2016) aimed at identifying the level of multiple intelligences among pupils of the year four and five primary. In addition, it aimed to also detect if there were statistically significant differences in the types of multiple intelligences in the study sample, Due to the difference in gender and academic level. A measuring instrument of the questionnaire was applied to a sample of 300 of fourth- and fifth-year primary students. The results revealed a high level of multiple intelligence and the existence of differences of statistical significance in the study sample due to gender and academic level features.

Ali's study in 2017 aimed at identifying the multiple intelligence profiles prevailing in the first and second secondary students in the province of Damascus. Besides, the study aimed to generate a statement of differentiation in multiple intelligences according to the gender, grade, and specialty variables. The study tool was implemented on a sample of 260 students. Its results revealed that the multiple intelligences prevailing in the first-grade secondary students was linguistic intelligence and then logical mathematical. As for second-grade secondary students, their dominant intelligence was social intelligence, hence, logical mathematical intelligence. The results revealed statistically significant differences due to the gender variable, logical intelligence of the males, and musical intelligence of the females. It further indicated that there were differences of statistical significance between students of the scientific and literary section. The bodily-kinesthetic intelligence and logical mathematical intelligence came to the benefit of the scientific section. The linguistic intelligences came to the benefit of the literary section.

Over the course of this study, Narad and Rani's research (2018) was reviewed for the relationship of multiple intelligence to academic achievement of students. Alongside this, we looked over 38 current scholarly articles from 1997 to 2018. Most of the studies were conducted at elementary, secondary, and college levels in India, Malaysia, Turkey, Iran, Poland, Oman, Indonesia, and Saudi Arabia. They had been conducted with respect to academic achievement in different subjects such as English, Mathematics, Science, Biology, Physics, etc. The review of literature revealed that "multiple intelligences" is a very vital factor in the overall as well as subject-wise academic achievement of students. The implication of the paper is that a multiple intelligence approach should be integrated at all levels of the education system for the development of a balanced personality of students.

Finally, a majority of studies has indicated the role of the influential theory of Howard Gardner. In the detection of students' individual abilities. Therefore, this theory is of great importance in the field of education across all stages of study and has covered many aspects that were not covered by previous theories. Many applications and studies emphasize the effectiveness of the theory in many educational aspects such as academic achievement, thinking, creativity, creative and critical thinking, communication and mathematical connection, and self-development, etc. (Fumham \& Shagabutdionva, 2012; Tammi, 2016; Abu Ahmed, 2014; Abu Zakiq, 2012; Barkati, 2009; Abdul Qader \& Hashim, 2007).

\section{Aim and Significance of the Study}

The world has advanced and science is constantly searching for new ways to make a better life available to the population. One of such methods to improve our lives with is defining and cultivating our unique intelligence set so that we can be better guided in our choices. Thus, scientists have investigated the depths of multi-intelligences and they have come up with several kinds. According to the value of this interesting realm of exploration, this study aimed to recognize the multi-intelligences at the Jordan University of Science and Technology through the variables of gender, academic year, and achievement.

\section{Study Problem}

The study sought to measure the level of multiple intelligences among the first-year students at the University of Science and Technology of Jordan and its relation to some variables. The study answered the questions below.

1- What is the degree of multiple intelligences among the students of Jordan University of Science and Technology?

2- Is there a statistically significant relationship between multiple intelligence levels and level of achievement?

3- Is there a statistically significant relationship between multiple intelligence levels and gender?

4- Is there a statistically significant relationship between multiple intelligence levels and academic year? 


\section{Methodology}

\subsection{Participants}

The participating students were 349 from Jordan University of Science and Technology, the participants consisted of 191 girls $(54.7 \%)$ and 158 boys $(45.3 \%)$. Also, $24.4 \%$ was from the first year, $35.5 \%$ was from the second, and then $40.1 \%$ from the third.

Table 1. The frequency of participants according to gender

\begin{tabular}{ccc}
\hline Gender & Frequency & (\%) percentage \\
\hline Male & 158 & 45.3 \\
Female & 191 & 54.7 \\
Sum & 349 & 100.0
\end{tabular}

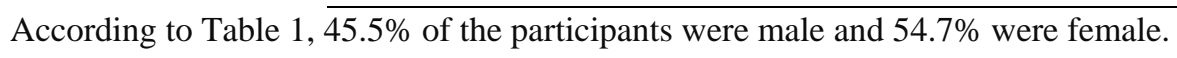

Table 2. The frequency of participants according to academic year

\begin{tabular}{ccc}
\hline Year & frequency & Percentage (\%) \\
\hline First & 85 & 24.4 \\
Second & 124 & 35.5 \\
Third and up & 140 & 40.1 \\
Sum & 349 & 100.0
\end{tabular}

According to Table 2, 24.4\% of the participants were from the first year and 35.5\% from the second, and $40.1 \%$ from the third year.

\subsection{Instruments}

The McKenzie scale for multiple intelligences

The researchers used the McKenzie scale for multiple intelligences (1999) and it consisted of 90 paragraphs split on 9 multiple intelligences, 10 paragraphs for each kind. For each paragraph, we used the Likert Items. The researchers translated the scale into the Arabic language and made sure that it was as close as possible to other scales in the Arabic language. The next table describe the McKenzie scale for multiple intelligences.

Table 3. The distribution of multiple intelligences on paragraphs

\begin{tabular}{cc}
\hline Dimensions & Paragraph \\
\hline Linguistic Intelligence & 1.10 .19 .28 .37 .46 .55 .64 .73 .82 \\
Logical-Mathematical Intelligence & 2.11 .20 .29 .38 .47 .56 .65 .74 .83 \\
Visual Intelligence. & 3.12 .21 .30 .39 .48 .57 .66 .75 .84 \\
Bodily-Kinesthetic Intelligence & 4.13 .22 .31 .40 .49 .58 .67 .76 .85 \\
Musical Intelligence & 5.14 .23 .32 .41 .50 .59 .68 .77 .86 \\
Interpersonal Intelligence & 6.15 .24 .33 .42 .51 .60 .69 .78 .87 \\
Social Intelligence & 7.16 .25 .34 .43 .52 .61 .70 .79 .88 \\
Natural Intelligence & 8.17 .26 .35 .44 .53 .62 .71 .80 .89 \\
Existential Intelligence & 9.18 .27 .36 .45 .54 .63 .72 .81 .90
\end{tabular}

\subsection{Methodology of the Study}

The study used descriptive analysis to measure multiple intelligences and answer the questions.

\section{Data Analyzed}

\subsection{Virtual Scale Honesty}

After translating the scale to Arabic language and edit to suit the objectives and questions of the study, and its participants., the researchers gave the scale to 10 professionals who had enormous experience about multiple intelligences and PhDs in education. They were also proficient at measurement and assessment, the Arabic language, 
statistic, and worked in the Yarmouk University and the Jordan University of Technology and Science. They had also improved on the appropriateness of the proposed data for the test by revising some statements.

\subsection{Reliability/Stability}

The stability of the test on multiple intelligences was obtained by extracting the stability parameters of the scale used in the internal consistency method by calculating the stability coefficient using the Cronbach-Alpha equation. Table 4 below shows the results of Internal stability.

Table 4. Reliability

\begin{tabular}{ccc}
\hline Dimension & Cronbach Alpha & $\begin{array}{c}\text { Number of } \\
\text { Paragraphs }\end{array}$ \\
\hline Linguistic Intelligence & 0.796 & 10 \\
Logical-Mathematical Intelligence & 0.816 & 10 \\
Visual Intelligence. & 0.780 & 10 \\
Bodily-Kinesthetic Intelligence & 0.789 & 10 \\
Musical Intelligence & 0.863 & 10 \\
Interpersonal Intelligence & 0.792 & 10 \\
Social Intelligence & 0.815 & 10 \\
Natural Intelligence & 0.739 & 10 \\
Existential Intelligence & 0.774 & 10 \\
Sum & 0.966 & 90
\end{tabular}

According to Table 4, we can see that the internal stability ranged from 0.739 to 0.863 for the dimensions of the scale. The total value of stability coefficients for all scale paragraphs reached. 0.966.

These results are acceptable and indicate the reliability and stability of the study scale. Sekaran (1984) asserts the quality of this measure if Cronbach alpha exceeds 60.0.

\section{Discussion and Conclusion}

7.1 The Results and Discussion

First: What is the degree of multiple intelligences among the students of Jordan University of Science and Technology?

To answer this question, the averages and standard deviations to the students' answers were calculated. Table 5 below shows the results.

Table 5. The means and standard deviations for the multi-intelligences scale

\begin{tabular}{cccc}
\hline Mean of domains & means & Standard deviation & result \\
\hline Linguistic Intelligence & 3.5 & 0.73 & accept \\
Logical-Mathematical Intelligence & 3.7 & 0.66 & accept \\
Visual Intelligence & 3.7 & 0.65 & accept \\
Bodily-Kinesthetic Intelligence & 3.8 & 0.65 & accept \\
Musical Intelligence & 3.4 & 0.86 & accept \\
Interpersonal Intelligence & 4.1 & 0.55 & accept \\
Social Intelligence & 3.5 & 0.73 & accept \\
Natural Intelligence & 3.7 & 0.62 & accept \\
Existential Intelligence & 3.9 & 0.64 & accept \\
Mean of Domains & 3.70 & 0.37 & accept
\end{tabular}

Table 5 shows the average range for all domains (3.70). That means the mean of the students' answers were accepted. 
Standard deviation for all domains are less than one standard deviation from the means. The highest mean was 4.1 for the Interpersonal domain, then the Existential Intelligence in the second rank, and in the third came the Bodily-Kinesthetic Intelligence, while the Musical domain got the least mean (3.4).

As we can see, the interpersonal intelligence was the heights domain. The researchers see that this is attributed because the university helps the students to plan for their future by guiding them and providing many courses on self-improvement.

Also, we can say that the society's culture, in general, helps in building a balanced personality that depends on self, whereas social and economic conditions have a huge effect on personality improvement and self-development.

The last domain was musical intelligence, also the university doesn't give the musical intelligence much care.

Besides that, the prevailing culture in Jordanian society does not encourage or care about the development of its music heritage. This is confirmed by many schools, both public and private, that do not publish and learn musical culture. Worse still, at university level, there is yet a lack of interest in the musical aspect of its students.

Those results came close with some researches like Al-Rashid (2014), which revealed that personal intelligence ranked first, then social and logical intelligence, linguistics, physical, physiological, spatial, and musical in the end. Also, from the study made by Saidi (2015), the results of the study indicated a difference in the levels of multiple intelligences in the study sample. Alawneh's work (2016) showed no statistically significant differences in the study sample in multiple intelligences, which corresponds with our findings.

Second: Is there a statistically significant relationship between multiple intelligence levels and gender?

To answer this question, a test was used, T-test for split samples, to check the differences due to gender. Table 6 shows that. 
Table 6. T-test for Equality of Variances for the students answers due to gender.

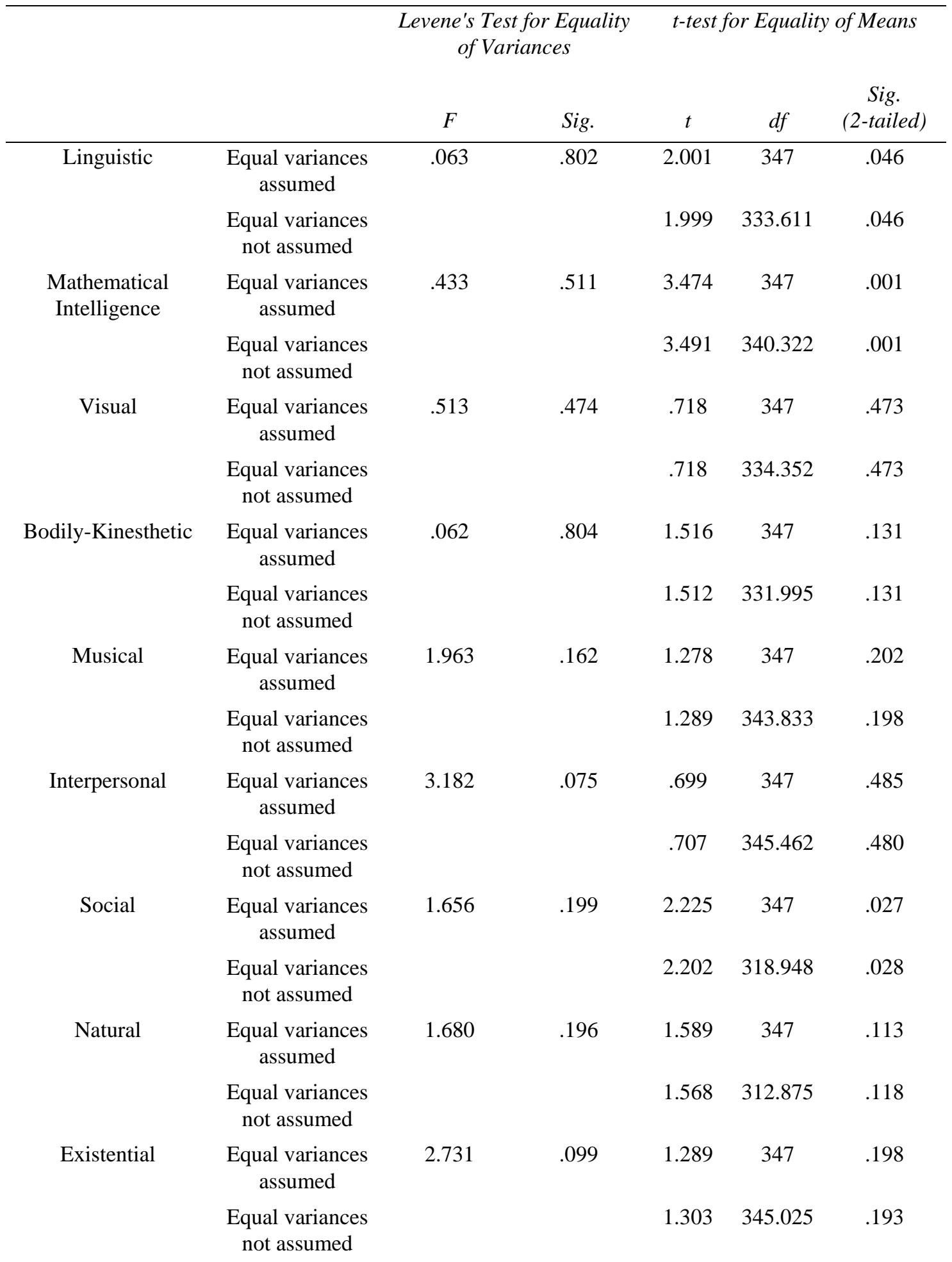

The results in Table 6 show that there aren't statistically significant differences $(\alpha \geq 0.05)$ in the students results due to gender based on level of the significant, which is more than 0.05 for all dimension. Thus, we accept the null hypothesis.

As we can see, there aren't statistically significant differences in the results, and this is due to the university's majors being appropriate to both girls and boys, who study in the university equally. Thus, there are no differences due to gender. The lack of a difference attributed to the gender variable occurs because the basic, secondary, and university 
education of the Jordanian system have a great match in terms of teaching methods and scientific content. Also, the culture of the Jordanian society, especially her customs, traditions, and religious reference, contributed to the absence of statistically significant differences. This study indicates that there are no statistically significant differences unlike many studies such as Alawneh's (2016), who found statistically significant differences in multiple intelligences in the study sample due to gender. Also, a study made by Zina in 2016 found the existence of different statistical significance in the study sample due to gender and academic level. Again, from the study of Ali in 2017, the results revealed statistically significant differences due to the gender variable. Yet again, Ryan's Study (2013) found that there were statistically significant differences according to gender in some domains.

Third: Is there a statistically significant relationship between multiple intelligence levels and academic year?

To determine if there were differences between the students' answers due to the academic year, a one-way Anova has been taken. Table 7 shows the results.

Table 7. One-way Anova to point out the differences between the students' answers

\begin{tabular}{|c|c|c|c|c|c|c|}
\hline \multicolumn{7}{|c|}{ ANOVA } \\
\hline & & $\begin{array}{l}\text { Sum of } \\
\text { Squares }\end{array}$ & $d f$ & $\begin{array}{l}\text { Mean } \\
\text { Square }\end{array}$ & $F$ & Sig. \\
\hline \multirow[t]{3}{*}{ Linguistic } & Between Groups & 1.358 & 2 & .679 & 1.271 & .282 \\
\hline & Within Groups & 184.745 & 346 & .534 & & \\
\hline & Total & 186.103 & 348 & & & \\
\hline \multirow{3}{*}{$\begin{array}{l}\text { Mathematical } \\
\text { Intelligence }\end{array}$} & Between Groups & .445 & 2 & .223 & .502 & .606 \\
\hline & Within Groups & 153.392 & 346 & .443 & & \\
\hline & Total & 153.837 & 348 & & & \\
\hline \multirow[t]{3}{*}{ Visual } & Between Groups & .939 & 2 & .470 & 1.105 & .332 \\
\hline & Within Groups & 147.010 & 346 & .425 & & \\
\hline & Total & 147.949 & 348 & & & \\
\hline \multirow[t]{3}{*}{ Bodily-Kinesthetic } & Between Groups & .150 & 2 & .075 & .177 & .838 \\
\hline & Within Groups & 146.577 & 346 & .424 & & \\
\hline & Total & 146.726 & 348 & & & \\
\hline \multirow[t]{3}{*}{ Musical } & Between Groups & 3.784 & 2 & 1.892 & 2.554 & .079 \\
\hline & Within Groups & 256.287 & 346 & .741 & & \\
\hline & Total & 260.071 & 348 & & & \\
\hline \multirow[t]{3}{*}{ Interpersonal } & Between Groups & .465 & 2 & .233 & .763 & .467 \\
\hline & Within Groups & 105.458 & 346 & .305 & & \\
\hline & Total & 105.923 & 348 & & & \\
\hline \multirow[t]{3}{*}{ Social } & Between Groups & 1.624 & 2 & .812 & 1.541 & .216 \\
\hline & Within Groups & 182.317 & 346 & .527 & & \\
\hline & Total & 183.941 & 348 & & & \\
\hline \multirow[t]{3}{*}{ Natural } & Between Groups & .276 & 2 & .138 & .355 & .701 \\
\hline & Within Groups & 134.108 & 346 & .388 & & \\
\hline & Total & 134.384 & 348 & & & \\
\hline \multirow[t]{3}{*}{ Existential } & Between Groups & .051 & 2 & .026 & .062 & .940 \\
\hline & Within Groups & 143.931 & 346 & .416 & & \\
\hline & Total & 143.982 & 348 & & & \\
\hline
\end{tabular}

The results in Table (7) shows that there aren't statistically significant differences $(\propto \geq 0.05)$ in the students results due to the academic year. 
Due to the results, there weren't any statistically significant differences. This is due to the fact that students have intelligence that got by education in schools, where they entered their majors based on what they want. And the educational system in schools is somewhat similar in university teaching, as most education is through traditional teaching, whether in universities or schools, which makes students have a certain type of intelligence.

Unlike this study, many studies showed statistical significance like Zina in (2016), And the existence of differences of statistical significance in the study sample. Due to gender and academic level. and the study of Abdul Qadir, Abu Hashem, (2007) showed statistically significant effect on the educational stage on multiple intelligences.

Fourth: Is there a statistically significant relationship between multiple intelligence levels and level of achievement?

To know if there were any statistically significant differences $(\alpha \geq 0.05)$ in the students results due to the achievement, One way ANOVA has been used, the results came as it's in table 8.

Table 8. One way ANOVA between the students answers due to achievement.

\begin{tabular}{|c|c|c|c|c|c|c|}
\hline \multicolumn{7}{|c|}{ ANOVA } \\
\hline & & Sum of Squares & $d f$ & Mean Square & $F$ & Sig. \\
\hline \multirow[t]{3}{*}{ Linguistic } & Between Groups & 12.289 & 6 & 2.048 & 4.030 & .001 \\
\hline & Within Groups & 173.814 & 342 & .508 & & \\
\hline & Total & 186.103 & 348 & & & \\
\hline \multirow{3}{*}{$\begin{array}{l}\text { Mathematical } \\
\text { Intelligence }\end{array}$} & Between Groups & 12.044 & 6 & 2.007 & 4.842 & .000 \\
\hline & Within Groups & 141.793 & 342 & .415 & & \\
\hline & Total & 153.837 & 348 & & & \\
\hline \multirow[t]{3}{*}{ Visual } & Between Groups & 8.522 & 6 & 1.420 & 3.484 & .002 \\
\hline & Within Groups & 139.427 & 342 & .408 & & \\
\hline & Total & 147.949 & 348 & & & \\
\hline \multirow[t]{3}{*}{ Bodily-Kinesthetic } & Between Groups & 8.497 & 6 & 1.416 & 3.504 & .002 \\
\hline & Within Groups & 138.229 & 342 & .404 & & \\
\hline & Total & 146.726 & 348 & & & \\
\hline \multirow[t]{3}{*}{ Musical } & Between Groups & 7.549 & 6 & 1.258 & 1.704 & .119 \\
\hline & Within Groups & 252.522 & 342 & .738 & & \\
\hline & Total & 260.071 & 348 & & & \\
\hline \multirow[t]{3}{*}{ Interpersonal } & Between Groups & 3.967 & 6 & .661 & 2.218 & .041 \\
\hline & Within Groups & 101.957 & 342 & .298 & & \\
\hline & Total & 105.923 & 348 & & & \\
\hline \multirow[t]{3}{*}{ Social } & Between Groups & 8.110 & 6 & 1.352 & 2.629 & .017 \\
\hline & Within Groups & 175.831 & 342 & .514 & & \\
\hline & Total & 183.941 & 348 & & & \\
\hline \multirow[t]{3}{*}{ Natural } & Between Groups & 7.053 & 6 & 1.176 & 3.157 & .005 \\
\hline & Within Groups & 127.331 & 342 & .372 & & \\
\hline & Total & 134.384 & 348 & & & \\
\hline \multirow[t]{3}{*}{ Existential } & Between Groups & 3.719 & 6 & .620 & 1.511 & .174 \\
\hline & Within Groups & 140.264 & 342 & .410 & & \\
\hline & Total & 143.982 & 348 & & & \\
\hline
\end{tabular}

The results in Table 8 shows that there isn't statistically significant differences $(\alpha \geq 0.05)$ in the students' results for the musical and existential dimension due to achievement, so we accept the null hypothesis. Also, we can see that there 
are statistically significant differences $(\propto \geq 0.05)$ in the students' results for the Linguistic, Mathematical Intelligence, Visual, Bodily-Kinesthetic, Bodily-Kinesthetic, and Natural due to achievement based on the level of significant, and it was less than 0.05 . In the light of this, we accept the alternative hypothesis which states that there is a statistically significant difference between the students' answers for the Linguistic, Mathematical Intelligence, Visual, Bodily-Kinesthetic, Bodily-Kinesthetic and Natural due to achievement.

And about the existential and musical intelligences, the culture, religion, customs and traditions prevailing in society do not help to spread, adopt, and show these types of intelligence among members of society, as the university's environment lacks the appropriate tools, places, and methods that encourage the display of these intelligence.

There is also a relationship between the rest of the domains because it is in line with the customs and traditions prevailing in society, as the educational system in the primary, secondary, and university theaters serves that.

Those results are close to the findings in some studies like Saidi's (2015) .The results of the study indicated a difference in the levels of multiple intelligences in the study sample. Also, from Narad and Rani's study (2019), it was found that multiple intelligences is a very vital factor as well as subject-wise academic achievement of students.

\section{Recommendations}

Based on the study results, researchers recommend that the Jordan University of Science and Technology should focus on the multi-intelligences and improve it for both male and female in the design of university courses.

Members of the Jordan University of Science and Technology should use various teaching methods and educational strategies that are appropriate for the multiple intelligences of students.

It will be necessary to pay attention to multiple intelligences in basic and secondary education at schools and providing the appropriate environment for students.

Conducting new researches on multiple intelligences and their relationship to a set of variables, such as choosing a university specialization, ...

\section{References}

Abdul Qader, F. \& Hashim, A. (2007). The general construction of intelligence in light of Gardner's classification and its relation to self-efficacy, problem solving and academic achievement among university students. Journal of the Faculty of Education - Zagazig, 55, 171-240. https://cutt.us/6WqpZ

Abu Ahmed, C., Assali, A. \& Qasem, N. (2014). The effect of using an educational strategy Based on the theory of multiple intelligences in the achievement of students in the sixth grade basic Nablus Governorate. In the content of the Arabic language curriculum and in developing their critical thinking skills. Master Thesis. An-Najah National University. https://cutt.us/HBhtF

Abu Zakiq, K. (2012). The strategies of multiple intelligences and their support for the development and quality of scientific curricula in universities to enhance creativity. The Ninth Arab Scientific Conference for Gifted and Talent People. Jordan, 2, 47-80.

Ali, K. \& Rahma, A. (2017). Profiles of multiple intelligences among secondary school students in the Governorate of Damascus. Al - Baath University Journal. Issue, 93(63), 129-169. https://cutt.us/LX9rw

Barkati, N. (2009). The impact of teaching using multiple intelligence strategies and six hats in academic achievement, communication and mathematical interdependence. The average third grade students in the city of Mecca. Ph.D, Thesis. Umm Al Qura University. Saudi Arabia.

Chen, J-Q. \& Gardner, H. (2005). Assessment based on multiple intelligences theory. In D. P. Flanagan (Ed.), Contemporary Intellectual Assessment: Theories, Tests, 77(102). New York: Guilford Press.

Fumham, A \& Shagabutdionva, K. (2012). Sex differences in estimating multiple intelligences in self and others: A replication in Russia. International Journal of Psychology, 47(6), 8-459 https://doi.org/10.1080/00207594.2012.658054

Göğebakan, D. (2003). How Students' Multiple Intelligences Differ in Terms of Grade Level and Gender. Master Thesis. The Graduate School of Social Sciences of Middle East Technical University, 13.

Jaber, A- H. (2003). Multiple intelligences and understanding - Development and deepening. Reference Series in Education and Psychology, (28). Dar El Fikr El Araby, Cairo.

Nard, Anshu \& Rani, Poonam. (2018). Gardner's Multiple Intelligences and Academic Achievement of Students: A Review of Literature. International Journal of Education, 11, 41-53. https://cutt.us/qJAi0 
McKenzie, W. (1999). Multiple Intelligences Inventory. http://surfaquarium.com/MI/inventory.htm

Rashid, F. (2014). Determination of multiple intelligences among female students of the Faculty of Science and Arts in the Saudi Arabia and their relation to some variables. Arab Journal of Excellence Development. Arab Council for gifted and talenteds, 5(9), 103-121. https://cutt.us/Xg3Gz

Rfeqah, ben Zina. (2016). The level of multiple intelligences among fourth-and fifth-year students in the primary stage. Master Thesis. Faculty of Humanities and Social Sciences, Department of psychology and Education Sciences. University of Kasdi Merbah Ouargla.

Saadi, A., Aljahore, N., Khataybeh, A. \& Almarzoqe, A. (2015). Patterns of Multiple Intelligences among Grade 12 Students at Ka'ab Bin Barsha School for General Education in the Sultanate of Oman. And their relation to academic achievement and their attitudes towards chemistry. Journal of the Federation of Arab Universities for Education and Psychologys, 13(3), 11-38. https://cutt.us/BnGT0

Saricaoğlu, A. \& Arikan, A. (2009). A study of multiple intelligences, foreign language success and some selected variable. Journal of Theory and Practice in Education Articles Makaleler ISSN: 1304-9496, 5(2), 110-122.https://cutt.us/cj9oD

Sekaran, U. (1984). Research method for managers: A skill buildings Approach, Wiley john and Sons Inc, $225-226$.

Shalk, A. (2002). A study of the relationship between multiple intelligences and achievement as measured by Delaware student testing program (DSTP) scores in reading, mathematics, and writing Ed.D, Wilmington college, (107).

Tamimi, I. \& Tamimi, A (2016). The impact of the use of the strategy of teaching on the basis of multiple intelligences on the collection of concepts jurisprudence among the eighth-grade students in Jordan. Zarqa Governorate as a model. Journal of Educational and Psychological Studies - Sultanate of Oman, 10(1), 48-65. https://doi.org/10.24200/jeps.vol10iss1pp48-65 